\title{
Smoking characteristics and cessation in patients with thromboangiitis obliterans
}

\author{
C.A. Jiménez-Ruiz1, L.C. Dale², J. Astray Mochales¹, L. Velázquez \\ Buendía 1 , I. de Granda Orive³, A. Guirao García 1
}

ABSTRACT: Smoking characteristics and cessation in patients with thromboangiitis obliterans. C.A. JiménezRuiz, L.C. Dale, J. Astray Mochales, L. Velázquez Buendía, I. de Granda Orive, A. Guirao García.

Aim. Describe the smoking characteristics and the results of a smoking intervention programme involving 27 cigarette smokers with Thromboangiitis Obliterans (TAO).

Methods. Clinical records of all cigarette smokers with TAO that attended our smoking treatment clinic from 1990 to 2004 were reviewed. Demographic and smoking characteristics, the type of smoking treatment received and its efficacy and safety up to 12 months was abstracted. Treatment consisted of the combination of behavioural and pharmacological treatment. The behavioural treatment was delivered in eight individual visits: one baseline visit and seven follow-up visits. Pharmacological treatment consisted of combinations of nicotine patches and nicotine gum (NRT) and/or bupropion. This is an'intent to treat' analysis. A descriptive analysis of the variables was performed. Qualitative variable relationships were tested using the $\chi$-square test for independence, or Fisher's Exact Test when expected values were less than five. Statistical significance was accepted at a level of $p<0.05$.
Results. 27 cigarette smokers ( 23 male and 4 female), mean (SD) age 36.07 (7.23), mean FTND-score 8.4 (1.4), smoked a mean of 29.6 (7.71) cigarettes daily. They attended our clinic a mean of $45.48(8.63)$ months after onset of TAO. Their mean number of attempts to stop was 3.22 (2.75). The continuous abstinence rate decreased from $29 \%$ at the end of treatment to $18.5 \%$ at 12 -month follow up. The seven day point prevalence abstinence rate at the $12^{\text {th }}$ month of follow up was $\mathbf{4 0 . 7 \%}$. We found that continuous abstinence at 6 and 12 months was more frequent among those with multiple previous stop attempts $(p=0.003$ and $p=0.001$, respectively). There were no significant differences in abstinence outcomes between groups. Incidence of adverse effects was similar to other smokers seeking treatment. All the smokers who achieved continuous tobacco abstinence had improvement in their disease and none of them underwent amputation, compared to $50 \%$ of those who resumed smoking and later required an amputation.

Conclusions. Continuous abstinence rates among treated cigarette smokers with TAO are relatively low, but abstinence does improve symptoms and reduce the likelihood of amputation. More aggressive treatment programmes need to be developed for this high risk, highly tobacco dependent population.

Monaldi Arch Chest Dis 2006; 65: 4, 217-221.

Keywords: Smoking cessation, thromboangiitis obliterans, Buerger's Disease.

1 Smokers Clinic. Institute of Public Health, Madrid, Spain.

2 Nicotine Dependence Centre, Mayo Clinic, Rochester, Minnesota, USA.

${ }^{3}$ Hospital de la Defensa, Valencia, Spain.

Correspondence: Carlos A. Jiménez-Ruiz; Smokers Clinic. Institute of Public Health; C/ Conde de Peñalver 96, Madrid 28006, Spain; e-mail: victorina@ctv.es

\section{Introduction}

Thromboangiitis obliterans (TAO) or Buerger's disease is a non-atherosclerotic, non-necrotizing, occlusive, inflammatory vascular disease. This often results in decreased blood flow to the distal extremities and subsequent increased risk of amputation. The mean age at onset of TAO is 34.5 years, and the male-female ratio is 7.5:1. The clinical picture typically occurs in young male smokers, with the onset of symptoms before the age of 40 to 45 years. It is characterised by claudication of the feet, legs, hands or arms and by acrally localised, non-healing ulcerations, which frequently prompt patients to see a physician [1].
The precise etiology of TAO is unknown. Genetic predisposition, autoimmune mechanisms and platelet dysfunction have all been suggested as potential etiologic factors [1]. Some cases of Buerger's disease in association with hypercoagulable states have also been described $[1,2]$. Nevertheless, the association between the use of tobacco, especially cigarettes, and the development of TAO is irrefutable $[1,3]$.

The most important component of the treatment of TAO is smoking cessation. The only proven strategy to prevent progression of the disease and avoid amputation is the complete discontinuation of cigarette smoking or the use of tobacco $[1,4,5]$. Substantial improvement of the dis- 
ease is associated with tobacco abstinence and progressive worsening with continued smoking. In a series of 89 patients with TAO, 52 (58\%) continued to smoke and 37 (42\%) stopped after diagnosis. Of the patients who stopped smoking, only 2 (5\%) underwent amputation in comparison with 22 (42\%) from the group that continued to smoke [6]. However, a substantial number of patients with TAO continue to use tobacco despite progression of disease and amputation $[7,8]$.

Descriptions of the smoking characteristics and the tobacco abstinence rates among smokers with TAO who received treatment for their tobacco use are scarce. The present paper describes a group of 27 cigarette smokers with TAO who received treatment in a tobacco intervention clinic in Spain. Analysis of smoking characteristics and the effectiveness and safety of tobacco interventions used are described.

\section{Methods}

This is a descriptive, retrospective report of 27 cigarette smokers suffering from TAO that attended a clinic specifically for treatment of their tobacco use from 1990 to 2004.

The clinical records of all cigarette smokers identified with TAO that attended the clinic from 1990 to 2004 were reviewed. Information concerning demographic and smoking characteristics, including sex, age, age at onset of tobacco use, number of previous attempts to stop, number of cigarettes smoked daily, number of pack/years, FTND score and expired air carbon monoxide $(\mathrm{CO})$ were collected. The type of tobacco treatment medications received, side-effects of these treatments and self-reported tobacco abstinence rates verified by expired $\mathrm{CO}$ at 2, 4, 8 and 12 weeks, 6 and 12 month follow-up were abstracted and analysed.

The tobacco intervention used consisted of the combination of behavioural and pharmacological treatment. The behavioural treatment was delivered in eight individual visits: an initial visit and seven follow-up visits. At the initial visit medical and smoking histories were obtained. The patient received intensive behavioural counselling, selfhelp materials, and a quit date was chosen. The strong relationship between TAO and tobacco consumption and tobacco abstinence as the most important aspect of treatment of TAO was emphasised to the patient. Pharmacological treatment was prescribed and patients were instructed in appropriate use. The initial visit lasted approximately 25-30 minutes.

At follow-up visits patients received additional intensive individual counselling. Patients were instructed in how to cope, manage stressful situations, and prevent relapse. Continuous abstinence and 7-day point prevalence abstinence and adverse effects of the medication were assessed. Each follow-up visit lasted approximately 10-15 minutes. Continuous abstinence was defined as not smoking even a puff from the quit-date. An expired air CO of $\leq 5 \mathrm{ppm}$ verified self-reports. Point prevalence abstinence was defined as not smoking during the last seven days and this self-report was verified by an expired air $\mathrm{CO}$ of $\leq 5 \mathrm{ppm}$.

Pharmacological treatment consisted of combinations of nicotine patches, nicotine gum and/or bupropion for 12 weeks. Ten patients received a combination of 16-hour nicotine patches and nicotine gum. Seven patients received a combination of 24-hour nicotine patches and nicotine gum. Ten patients used a combination of 16 hour nicotine patch, nicotine gum and bupropion.

\section{Statistical Analysis}

A descriptive analysis of the variables was performed. We did an 'intent to treat' analysis, considering those lost to follow-up as smokers. Measurements of qualitative variables are expressed in absolute values and as percentages, while measurements for continuous quantitative variables are given as means and standard deviations. Qualitative variable relationships were tested using the $\chi$-square test for independence, or Fisher's Exact Test when expected values were less than five. Statistical significance was accepted at a level of $\mathrm{p}<0.05$.

\section{Results}

\section{Demographics and smoking characteristics}

Twenty-seven smokers (23 male and 4 female), mean $( \pm$ SD) age 36.07 (7.23), attended our clinic a mean of 45.48 (8.63) months after having been diagnosed with TAO. They smoked a mean of 29.6 (7.71) cigarettes daily, smoked a mean of 29.43 (12.14) pack/year. They had a mean FTND score of 8.4 (1.4) and a mean value of 30.8 (6.3) ppm of expired air $\mathrm{CO}$ at their initial visit. The mean number of previous stop attempts was 3.2 (2.7). Five had never tried to quit.

\section{Continuous abstinence}

Table 1 shows the continuous tobacco abstinence rate at 12-month follow-up by the type of pharmacological treatment received. The rate of continuous abstinence declined progressively from $70 \%$ at the end of the 4th week, $29 \%$ at the end of pharmacological treatment and $18.5 \%$ at the $12^{\text {th }}$ month of follow-up. There were no significant differences in the continuous abstinence rate based on type of nicotine patch received $(p=0.86$ at 6 months and $\mathrm{p}=0.94$ at 12 months). Comparison between the group who received only NRT and the group who received combination therapy (NRT plus bupropion) did not demonstrate any differences $(p=0.47$ and $p=0.62$ at 6 and 12 months, respectively).

There was no relationship between age, sex, number of cigarettes smoked daily, level of $\mathrm{CO}$ in expired air or FTND-score and success or failure. We, only found that continuous abstinence at 6 and 12 months follow up was higher among those with multiple previous stop attempts. $(\mathrm{p}=0.003$ and $\mathrm{p}=0.001$, respectively) 
Table 1. - Continuous abstinence rate. Number of abstainers at each visit. 'Intention to treat'

\begin{tabular}{lccccc}
\hline Treatment & $\mathbf{4}$ weeks & $\mathbf{8}$ weeks & $\mathbf{1 2}$ weeks & $\mathbf{6}$ months & $\mathbf{1 2}$ months \\
\hline $\begin{array}{l}16 \mathrm{H} \mathrm{NP} .+\mathrm{NG} \\
\mathrm{N}=10\end{array}$ & 7 & 4 & 3 & 2 & 2 \\
\hline $24 \mathrm{H} \mathrm{NP}+\mathrm{NG}$ & $70 \%$ & $40 \%$ & $30 \%$ & $20 \%$ & $20 \%$ \\
$\mathrm{~N}=7$ & 5 & 3 & 2 & 2 & 1 \\
\hline $\mathrm{B}+16 \mathrm{NP}+\mathrm{NG}$ & $71 \%$ & $43 \%$ & $28,5 \%$ & $28,5 \%$ & $14 \%$ \\
$\mathrm{~N}=10$ & 7 & 4 & 3 & 2 & 2 \\
\hline Total $(\mathrm{n}=27)$ & $70 \%$ & $40 \%$ & $30 \%$ & $20 \%$ & $20 \%$ \\
\hline
\end{tabular}

$16 \mathrm{H} \mathrm{NP}=16$ hour-nicotine patch; $24 \mathrm{H} \mathrm{NP}=24$ hour-nicotine patch; $\mathrm{B}=$ bupropion; $\mathrm{NG}=$ nicotine gum.

\section{Point prevalence abstinence rate at $12^{\text {th }}$ month follow up}

At the $12^{\text {th }}$ month of follow up the 7-day point prevalence, the abstinence rate was $40.7 \%$ (11 out of 27). There were no significant differences in the point prevalence abstinence rate based on type of nicotine patch received. Comparison between the group who received only NRT and the group who received combination therapy (NRT plus bupropion) did not demonstrate any differences.

\section{Use of treatment}

Nicotine patches plus nicotine gum therapy were prescribed to 17 patients. Twelve completed the prescribed course of treatment. 5 of the $17 \mathrm{pa}-$ tients who commenced this treatment did not return for visits and were lost to follow-up. The combination of nicotine patches, bupropion and nicotine gum were prescribed to ten patients, seven of whom completed treatment. Three out of ten patients who commenced this treatment did not return for visits and were lost to follow-up. We did not find significant differences between treatment groups.

\section{Incidence of Adverse Effects}

Twelve patients experienced adverse effects: 7 out of $17(41 \%)$ who used NRT alone and 5 out of $10(50 \%)$ who used NRT plus bupropion. There were no significant differences between types of medication: $p=0.4$; OR 95\% CI 1,4 (06-2.0). Those who experienced an adverse event were more likely to be continuously abstinent than those who did not experience an adverse effect (OR 0,179 95\% CI, 0,032-0,985; $\mathrm{p}=0.04)$. Those with greater pack/years of smoking also experienced more adverse events $(p=0.001)$. Insomnia was the most common adverse effect among those who were taking bupropion, and pruritis and rash at the patch site among those treated with nicotine patches. There were no reports of increased TAO symptoms such as claudication that could be attributed to the medications. No one discontinued treatment because of an adverse event.

\section{Clinical Outcomes}

One year of clinical outcome information was available for 19 of 27 patients. Five were abstinent from smoking and 14 continued smoking. All of the abstainers noted improvement in their symptoms and none of them had undergone amputation. In contrast, 7 out of $14(50 \%)$ who continued smoking required one or more amputations.

\section{Discussion}

In this paper, we describe the characteristics and outcomes of 27 cigarette smokers with TAO who were treated in an outpatient clinic specialising in the treatment of tobacco use. We present the results in an intent-to-treat analysis. To our knowledge this is the first series of smokers with TAO that describes tobacco treatment outcomes for patients with that disease.

This was a group of highly dependent, primarily male smokers with heavy cigarette use who had tried to stop a number of times before (only five had made no previous stop attempts). In a recent epidemiologic, multi-center, population-based Spanish study that we conducted to analyse the differences in smoking characteristics between healthy smokers and smokers with COPD, we found that the mean number of cigarettes smoked daily was 24.2 in the group of smokers with COPD and 18.5 in the group of "healthy smokers" [9]. We also found that only $10 \%$ of the "healthy smokers" and $28 \%$ of the COPD smokers had a FTND score of $\geq 7$. In our current study, the mean number of cigarettes smoked daily was higher $(29.6 \mathrm{cpd})$ and all the patients had FTND scores of $>8$. (FTND is a measure of nicotine dependence: a score of 6 or more indicates severe nicotine dependence.) Clearly, this sample of patients with TAO is a selfselected sample comprised of those smokers who demonstrated such a heavy dependence on tobacco that they were not able to quit previously in spite of suffering from this disease.

This heavy dependence is reflected in the relatively low continuous abstinence rates achieved with treatment by this population of cigarette smokers. The continuous tobacco abstinence rate 
declined from $70 \%$ at 4 weeks, $29 \%$ at 12 weeks, $22 \%$ at 6 months and $18.5 \%$ at 12 months after starting treatment. This is in contrast to the results in a large group of Spanish smokers who received less intensive treatment and yet achieved continuous abstinence rates of $53 \%$ and $38.8 \%$ at 3 and 6 months, respectively [10]. They smoked a mean of 25.2 cigarettes daily and more than $50 \%$ of them had a FTND score of $<6$. Our outcomes, however, are consistent with several other series of smokers with TAO demonstrating continued smoking despite progression of disease [6]. In a group of 26 patients with TAO only $19 \%$ could stop smoking and in another series of 39 patients only $2(5 \%)$ discontinued tobacco use [7,8]. This was an intent-to-treat analysis, considering those lost to follow-up as smokers so our results are conservative as some of those who did not return could have stopped smoking because of our intervention. When we consider 7-day point prevalence abstinence rate at the $12^{\text {th }}$ month follow up, the result is more optimistic at $40.7 \%$. This is in accordance with the relapsing and remitting nature of the disease, so many of those who relapsed at the beginning were abstinent again at one year follow up. However, clearly, complete and permanent abstinence must be the ultimate goal of treatment for this high-risk population of smokers.

Our prescribed treatment consisted of a combination of behavioural, chemical dependence and relapse prevention therapy. Components of the behavioural treatment included eight individual sessions addressing the strong relationship between TAO and smoking, stress management, coping strategies for high risk situations, social and family support and relapse prevention strategies. Although 19 patients used pharmacological treatment for the recommended three months, only eight (42\%) of them maintained continuous abstinence for those 12 weeks. The rest (11 patients) relapsed intermittently during the treatment period and resumed smoking completely between the $3^{\text {rd }}$ and $4^{\text {th }}$ months of follow-up. Despite their serious disease, eight patients chose not to continue the treatment programme and subsequently were lost to follow up.

Our finding of $6^{\text {th }}$ and $12^{\text {th }}$ months continuous abstinence more frequent among those with multiple stop attempts has also been noted by others [11]. It is known that each quit attempt can provide the smoker with information and skills that can be used more properly in future attempts to stop.

In this small sample, we did not find any relationship between long-term tobacco abstinence and the type of pharmacological treatment used. The efficacy of NRT alone was similar to the efficacy of the combination of NRT and bupropion. Adverse effects of the pharmacotherapy occurred in the same proportion as in treated smokers in general [12], but were more frequent in those who higher pack/years of smoking. It is important to note that we did not find an increase in TAO symptoms (such as claudication) while patients were on NRT.

The importance of treating tobacco use in patients with TAO cannot be overstated. None of the patients who succeed in continuous abstinence underwent amputation and all of them had improvement in their symptoms. In contrast, $50 \%$ of those who continued smoking suffered amputations. Although during the last decade, it was proposed that the use of nicotine replacement could aggravate TAO [1], more recently the use of NRT in patients with TAO and other cardiovascular diseases has been demonstrated to be safe $[6,13-17]$. The high levels of dependence demonstrated by this sample of patients and the relatively low success rates achieved with a fairly intensive outpatient treatment programme suggests we need to explore even more aggressive treatment for this population of patients who at very high risk of morbidity and mortality as a result of their tobacco use. Medication use for longer than 12 weeks, and/or higher doses of nicotine replacement therapy may increase tobacco abstinence rates in this highly dependent population [18]. An inpatient treatment programme, utilising higher doses of medications in combination with more intensive individual and group counselling may be more appropriate for this population $[15,19]$. In such a setting, patients could also be monitored much more closely for adverse effects and medication adjustments made more quickly. This approach to treatment may seem extreme, but for patients with TAO this may provide the greatest chance of achieving tobacco abstinence and avoiding amputation and early death.

In this paper, we describe the characteristics and outcomes of 27 cigarette smokers with TAO who received treatment for smoking cessation. Its major contribution is the finding that the smokers with this disease are so extremely dependent and that no patient that stopped smoking needed amputation. In the population of smokers there is only $1 \%$ of smokers with such dependence [20].

\section{References}

1. Olin JW. Current concepts: Thromboangiitis Obliterans (Buerger's Disease). New Engl J Med 2000; 343:864869.

2. Papa MZ, Adar R. A critical look at Thromboangiitis Obliterans (Buerger's Disease). Vasc Surg 1992; 5: 1-18.

3. O'dell JR, Linder J, Markin RS, Moore GF. Thromboangiitis Obliterans (Buerger's Disease) and smokeless tobacco. Arth Rheum 1987; 30: 1054-1056.

4. Shionoya S. What is Buerger's Disease? World J Surg 1983; 7: 544- 551.

5. Olin JW, Young JR, Graor RA, Ruschhaupt WF, Bartholomew JR. The changing clinical spectrum of Thromboangiitis Obliterans (Buerger's Disease). Circulation 1990; 82: Suppl IV: 8.

6. Joyce JW. Buerger's Disease (Thromboangiitis Obliterans). Rheum Dis Clin North Am 1990; 16: 463-470.

7. Mills JL, Taylor LM, Poter JM. Buerger's Disease in the modern era. Am J Surg 1987; 154: 123-129.

8. Grove WJ, Stansby GP. Buerger's Disease and cigarette smoking in Bangladesh. Ann Royal College Surg Engl 1992; 74: 115-117.

9. Jiménez-Ruiz CA, Masa F, Miravitlles M, et al. Smoking characteristics: Differences in attitudes and dependence between healthy smokers and smokers with COPD. Chest 2001; 119: 1365-1370. 
10. Barrueco M, Jiménez-Ruiz CA, Palomo L, Torecilla M, Romero M, Riesco JA. Abstinencia continua y puntual en el tratamiento farmacológico del tabaquismo en la práctica clínica. Med Clin (Barc) 2004; 123: 662-6.

11. Dale LC, Glover ED, Sachs DP, et al. Bupropion for smoking cessation. Predictors of successful outcome. Chest 2001, 119: 1357-1364.

12. George TP, O’Malley SS. Current pharmacological treatment for nicotine dependence. Trends Pharm Sci 2004; 25: 42-48.

13. Barrueco M, Jiménez-Ruiz CA, Palomo L, Torecilla M, Romero M, Riesco JA. Adverse effects of pharmacologic treatment for nicotine addiction. Nicotine Tob Res 2005; 7: 335-42.

14. Lie JT. Thromboangiitis Obliterans (Buerger's Disease) and smokeless tobacco. Arth Rheum 1988; 31: 812-813.

15. Hooten MW, Bruns HK, Hays JT. Inpatient treatment of severe nicotine dependence in a patient with Thromboangiitis Obliterans (Buerger's Disease). Mayo Clinic Proc 1998; 73: 529-532.

16. Rennard SI, Daughton D, Windle J. Toxicity of nicotine replacement in patients with coronary artery disease. In Nicotine safety and toxicity. Benowitz NL (ed). New York Oxford. Oxford University Press. 1998; pp: 49-53.

17. Working Group for the study of Transdermal Nicotine in patients with coronary artery disease. Nicotine replacement therapy for patients with coronary artery disease. Arch Intern Med 1994; 154: 989-95

18. Dale LC, Hurt RD, Offord KP, Lawson GM, Croghan IT, Schroeder DR. High-dose nicotine patch therapy: Percentage of replacement and smoking cessation. JAMA 1995; 274: 1353-1358.

19. Hurt RD, Dale LC, Offord KP, Bruce KP, McClain FL, Eberman KM. Inpatient treatment of severe nicotine dependence. Mayo Clinic Proc 1992; 67: 823-8.

20. John U, Meyer C, Hapke U, Rumpf HL, Schumann A, Adam C, Alte D, Ludemann J. The Fagerström test for nicotine dependence in two adults population samplespotential influence of lifetime amount of tobacco smoked on the degree of dependence. Drug Alcohol Depend 2003; 71: 1-6.

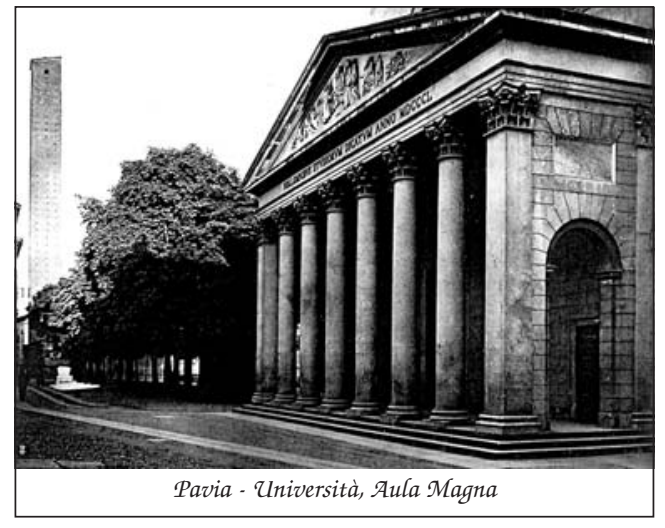

